\title{
Investigations regarding the lowering of specific intellectual property risks identified in the production process
}

\author{
Ramona Pakocs ${ }^{1, *}$, Nouraş Barbu Lupulescu ${ }^{1}$ \\ ${ }^{1}$ Transilvania University of Brasov, Department of Manufacturing Engineering, Mihai Viteazu No.5, \\ Braşov, Romania
}

\begin{abstract}
The main purpose of this research is to decrease the emergence of specific intellectual property risks within the production process as well as increasing risk management performance of IP by preventing them. In order to achieve this, previous studies regarding the main specific intellectual property risks from industrial companies were analyzed together with their managerial methods as well as the possibility of reducing their emergence. As a result of the research conducted were identified five types of intellectual property risks that have a high potential of emergence in the production process, namely: the risk of production of goods in violation of IP rights; the know-how, production knowledge and trade secret disclosure risk; the technological risk of unprotected utility models; the technological risk of unprotected integrated circuits topographies and finally the risk of product counterfeit. In order to achieve the main purpose of our investigation, we have proposed new formulas for estimating the specific intellectual property risks identified in the production process. Their purpose was to minimalize the risk's negative effects on industrial companies and to increase the managerial performance from the intellectual property domain through a new type of management appropriately named: intellectual property management. The research is finalized with a case study regarding the lapse of rights of a patented invention. Based on a case analysis, it was proved that the exploitation of an invention without a contract represents a counterfeit.
\end{abstract}

\section{Introduction}

Managing specific intellectual property risks represents nowadays a really delicate and complex problem due to the continuous development of new technologies.

Acknowledging the importance of the probability of apparition of specific production risks and the interest toward preventing them should be a part of the priority objectives of each industrial company's management plan.

Based on previous national and international investigations from specialty literature [1, $2]$, as well as from certain intellectual property analysis and case studies [3-9], it can be

\footnotetext{
*Corresponding author: ramona.pakocs@,unitbv.ro
} 
observed that the specific intellectual property production risks are acknowledged at a managerial level only after they were already present. This problem is mainly encountered in industrial companies and its consequences can be extremely negative over the financial situation and can increase the bankruptcy risk.

An investigation based on the questionnaire method was thus realized in order to identify the most common specific intellectual property production risks from certain industrial companies.

A long national and international investigation [3, 4], that has interviewed 258 managers who lead companies specialized in production activities has led to important results regarding the categories of specific intellectual property production risks. As such, the study has emphasized the most threatening risks, as follows (Figure 1):

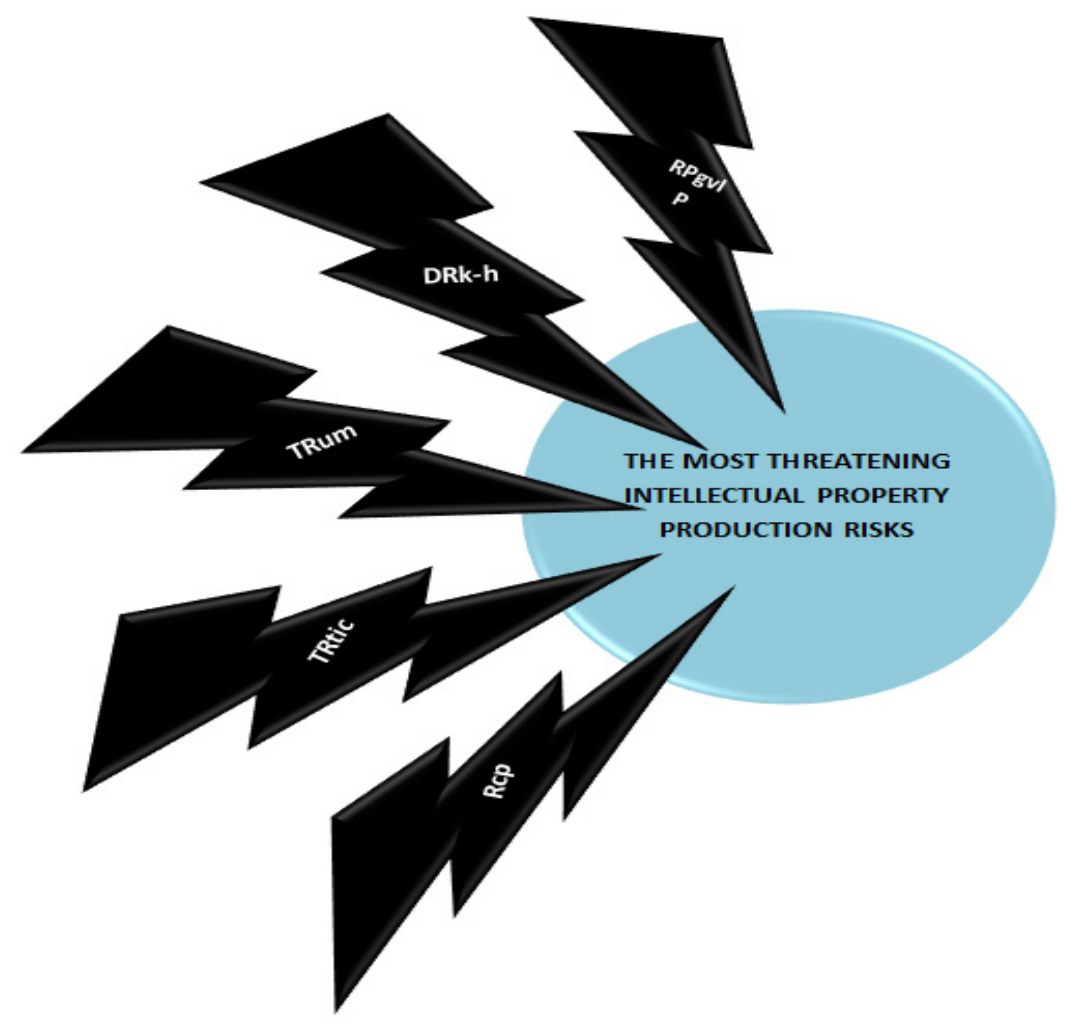

Fig. 1. The most threatening IP production risks.

Where:

- RpgvIP = risk of production of goods in violation of IP rights;

- $D R k$ - $h=$ disclosure risk of know-how, knowledge of production, trade secret;

- TRum $=$ technological risk of unprotected utility models;

- TRtic $=$ technological risk of unprotected topographies of integrated circuits;

- $R c p=$ risk of counterfeit of products.

Based on some previous studies [3-6], a series of specific intellectual property risks were identified in the product realization process from within the Quality Management System, namely: risk of production of goods in violation of IP rights; disclosure risk of know-how, knowledge of production, trade secret; technological risk of unprotected utility models; technological risk of unprotected topographies of integrated circuits and risk of counterfeit of products. These risks are rendered in Figure number 2, as follows: 


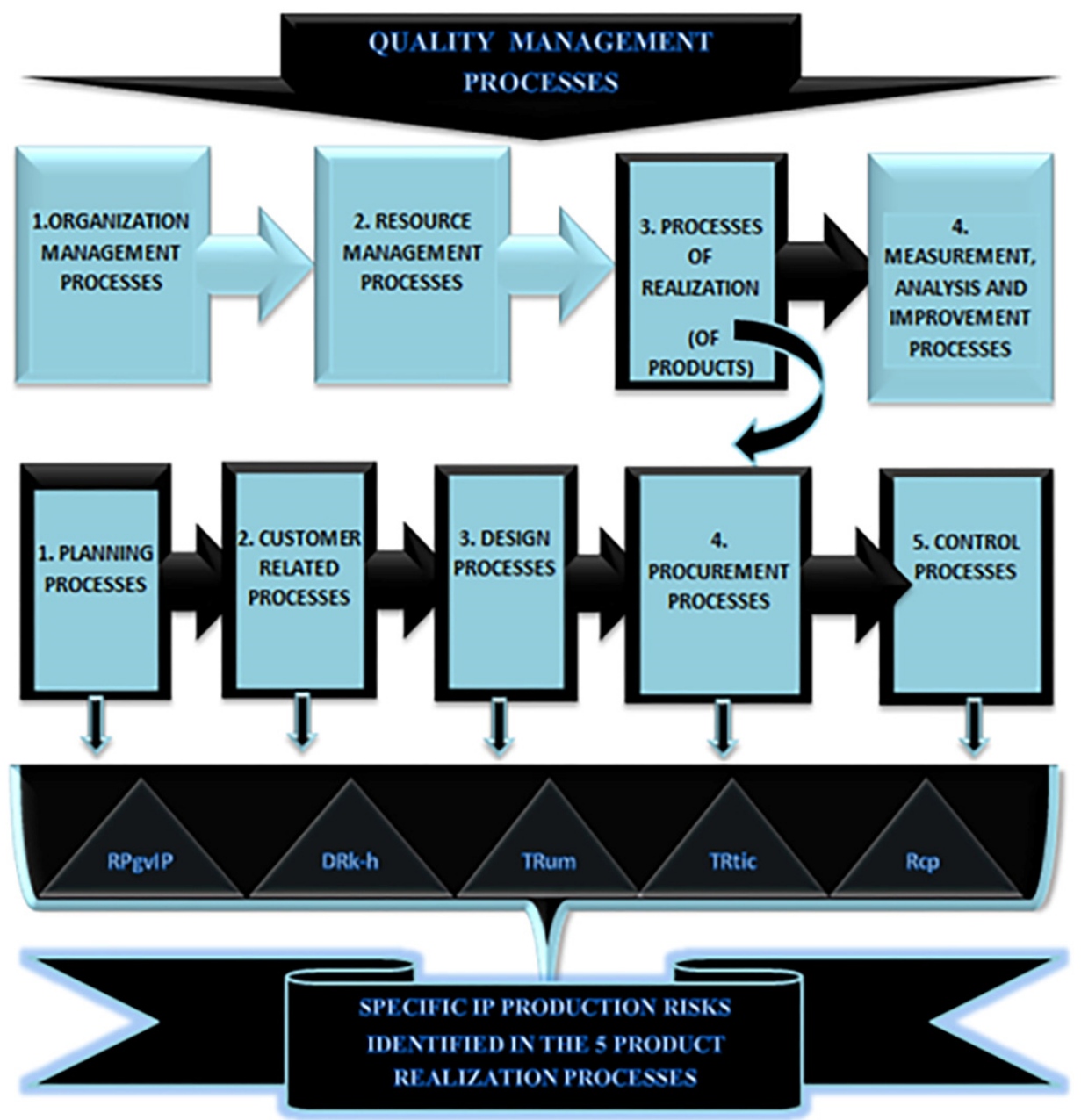

Fig. 2. Specific IP production risks identified in 5 product realization processes [3].

Growing the managerial performance can be achieved by implementing a quality risk and intellectual property management that leads to excellency. This also increases the competition on the targeted market through the increase of the quality of the fabricated products, by reducing the production risks that also include intellectual property risks [11, 12] that can appear in the production process (identified in Figure 2) and through an intelligent management of all intellectual property actives that capitalizes them and leads to an increase of financial revenues. 


\section{Managing specific intellectual property production risks}

The management of specific intellectual property production risks can be achieved through (Figure 3):

\section{MANAGING SPECIFICINTELLECTUAL PROPERTY PRODUCTION RISKS:}

\begin{abstract}
A. Analyzing the risk factors (the leadership can thus fnow the probable specific intellectual property production risks thatcan affect the cospany's well. functioning Based on [5], the main factors that influence the specific intellectual property risks are the following - sot monitoring the market; - realizing or wrongy nezptiating transfer or license contracts, or any contracts regarding ownership or rigts transfer, or exployees contracts:

- disloyal cospetition acts either froe the fins townads the conpetitor market, or froen the market towards the firn:

- under evaluating or over evaluating negotiable intang ble actives that can lead to significant losses in participatingat joint-venture contracts or even not signing then:

- violating (pirating) author rights tither by the finm towneds the cospetition. market, either by representatives or persons froen the coenpetition market towneds the firm: - the countefeit of company brand brands or products/services; - the counteffeit of patented inventions:

- the counteffeit of the industrial design
\end{abstract}

Fig. 3. Managing specific intellectual property productions risks.
B Elaborating managerial plans for the prerention of specific intellectual property risks (in order to. sedvas their consequences). In order to elaborate a managerial plan for the prevention of specific intellectual property risks, the protection of the cospany's intellectua! property regerdingits fabricated products is mandatory.

In order to achieve this, the ispleasentation of a managerial strategy for the prev eation of specific intellectual property production risks is aecessary by respecting the following steps:

a) Analyzing the products and establisting the possibility of proacting thase intellectual property objets: patents, utility $=0 d a t s$ brands, drawing =odals, integated circuit topogaphies, author rigts tic

b) Realizinga docusentad research.

c) Interpoeting the docusented research after it is realizad at OSDMC

d) Sugzasting an intellectua! propety protection stratezy based on the coopany's interests

e) Realizing the protection docusentation for the coopuny's IP actives in order to register thes at OSDC

1) Responding to OSD! notification and payingleg! taxes for obtaining the solicited protection titles. g) Following counterftit actions.

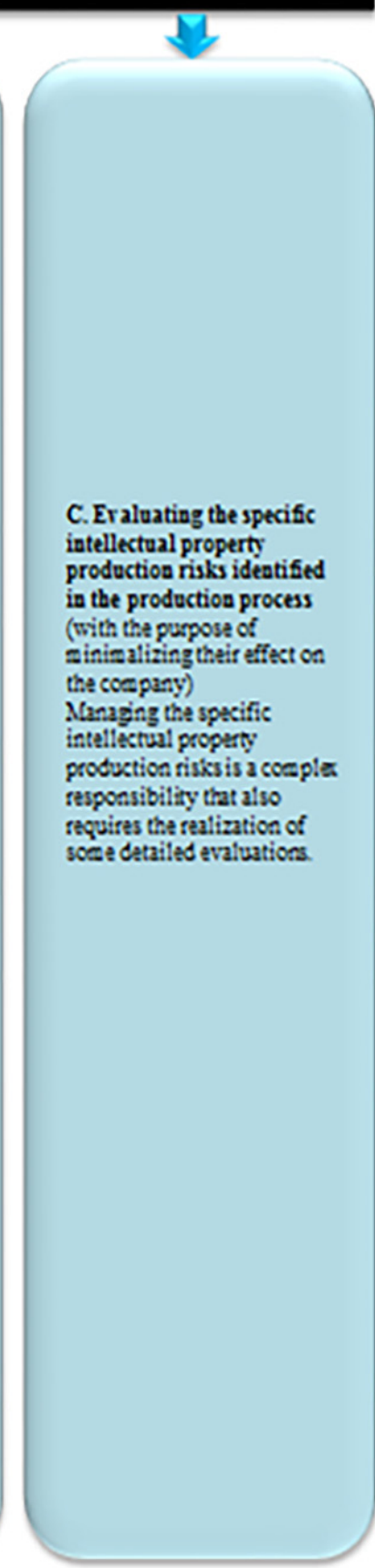

C. Eraluating the specific intellectual propert production risks ideatifed in the production process (with the punpose of minimalizing their effect on the coespany)

Managing the specific production risks is a cosple responsibility that also sequires the fealization of soee detailed evaluations 
A more complex theoretical evaluation was proposed in a previous research [3], where 3 situations for the detection of specific IP production risks were analyzed and new formulas were proposed for their evaluation.

In order to exemplify we will choose the Disclosure risk of know-how, knowledge of production, trade secret (noted $\boldsymbol{D} R \boldsymbol{k}-\boldsymbol{h}$ ) identified in the product realization process. The situations of know-how, production knowledge, trade secret disclosure risk (DRkh), based on their apparition time (moment) [3]:

1. detecting DRk-h in the anticipation of the production process.

2. detecting DRk-h in the production process.

3. detecting DRk-h in the production's commercialization process.

Based on the $3 \boldsymbol{D R} \boldsymbol{k}-\boldsymbol{h}$ detection moments from the production process, we propose the following evaluation hypothesis in which the following indicators are used:

$P A=$ probability of risk apparition;

$F R p i=$ IP risks frequency;

$I R p i=$ IP risks intensity;

$T R p i=$ IP risks detection time (moment);

FrpiD = IP risks decreasing cumulated frequency;

FrpiC = IP risks increasing cumulated frequency;

FrpiM = IP risks average frequency;

TRpi $\min =$ IP risks detection time (moment) in the anticipation stage;

TRpi $\max =$ IP risks detection time (moment) during the production process;

TRpi average $=$ IP risks detection time (moment) in the production commercialization process.

In our case, the proposed general formula for the specific $\boldsymbol{D} \boldsymbol{R} \boldsymbol{k}-\boldsymbol{h}$ production risks is [3]:

$$
D R_{k-h}=P A * \frac{F R_{P I} * I R_{P I}}{T R_{P I}}
$$

Hypothesis 1: Detecting DRk-h in the anticipation stage of the production process. In this stage [3]:

$P A=50 \%$

$$
F R_{P I} D=\sum_{X_{1<X}} R p i 1+R p i 2+\cdots R p i N\left(T R_{P I} \min \right)
$$

TRpi $\min =0$

IRpi $\min =0 \%$

Results that [3]:

$$
D R_{k-h}=P A * \frac{F R_{P I} D * I R_{P I} \min }{T R_{P I} \min }
$$

In this situation $\boldsymbol{D} \boldsymbol{R} \boldsymbol{k}-\boldsymbol{h}=0 \Rightarrow$ detecting $\boldsymbol{D} \boldsymbol{R} \boldsymbol{k}-\boldsymbol{h}$ in the anticipation stage leads to the possibility of reducing this risk to 0 . [3]

Hypothesis 2: Detecting DRk-h in the production process time.

In this stage [3]:

$P A=50 \%$

$$
F R_{P I} M=\frac{F R_{P I} D+F R_{P I} C}{2}
$$

FRpiM $=50$

TRpi average $=50$

IRpi $=50 \%$ 
Results that [3]:

$$
D R_{k-h}=P A * \frac{F R_{P I} M * I R_{P I} \text { average }}{T R_{P I} \text { average }}
$$

In this situation $\boldsymbol{D} \boldsymbol{R} \boldsymbol{k}-\boldsymbol{h}=50=>$ detecting $\boldsymbol{D} \boldsymbol{R} \boldsymbol{k}-\boldsymbol{h}$ within the production process can lead to a great loss of the enterprises capital $\geq 50 \%$. [3]

Hypothesis 3: Detecting DRk-h in the production's merchandising process.

In this stage [3]:

$P A=50 \%$

$$
F R_{P I} C=\sum_{X_{1, X_{\max }}} R p i 1+R p i 2+\cdots R p i N\left(T R_{P I} \max \right)
$$

FRpiC $=100$

TRpi $\max =100$

IRpi $=100 \%$

Results that [3]:

$$
D R_{k-h}=P A * \frac{F R_{P I} C * I R_{P I} \max }{T R_{P I} \max }
$$

In this situation the $\boldsymbol{D} \boldsymbol{R} \boldsymbol{k}$ - $\boldsymbol{h}$ 's impact on the company can be of $100 \%=>$ detecting $\boldsymbol{D} \boldsymbol{R} \boldsymbol{k}$ $\boldsymbol{h}$ in the merchandising stage can lead to losses of up to $100 \%=>$ the company's bankruptcy risk grows considerably [3].

We must specify the fact that this study is just a general example. The evaluation differs based on the identified production risk and other factors, depending on each case.

In order to exemplify a real situation for the apparition of a specific intellectual property production risks, a case study was chosen based on a specialized expertise [4-8].

\section{Analyzing a case study regarding a patent invention's lapse of rights}

The subject of this study is represented by the evolution and extension of the engineering work on the trajectory "project-patented invention-technical work" as a result of a patent invention's lapse of right $[3,6,7]$.

The case study's subject concerns the patent invention number " $x$ " from 26.04.1982 Hydraulic order block (Figure 4), owned by ALFA company and offers solutions that can be applied within large companies from the machine constructing industry that were once owned by the state, but avoided from unknown motives. [3, 6, 7] We would like to mention that the case study has been developed in Romania.

On 21.09.1981 company ALFA requires from OSIM (State Office for Inventions and Trademarks in Romania) the urgent patent of an invention that 2 engineers have projected and then cession based on Law number 62 from 1974 regarding inventions and innovations (This Law is applied in Romania). According to the law, the invention patent was assigned but without the right of exploiting the object of the invention patent $[3,6,7]$.

The inventors are remunerated, according to the law from that time until the date of 01.04.1983. 


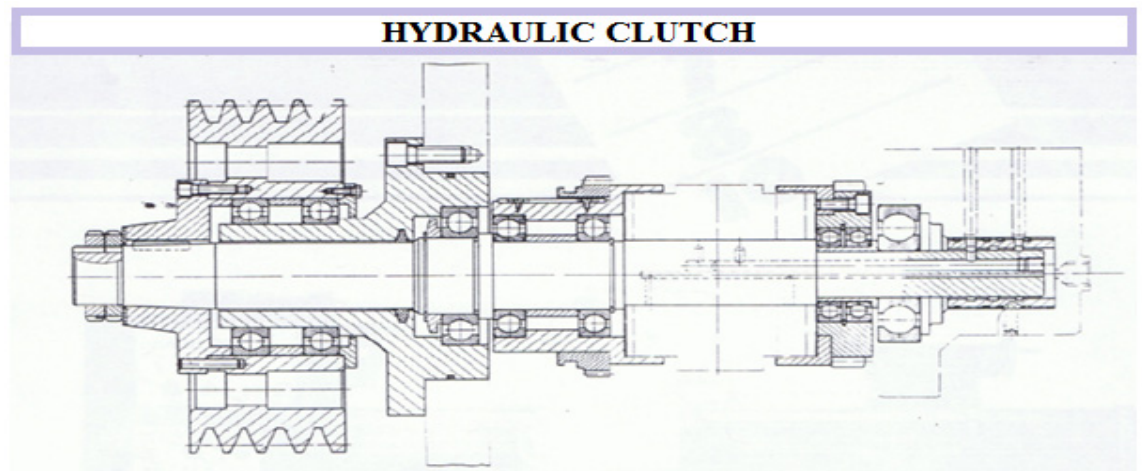

Fig. 4. Hydraulic clutch, subject of Patent- Hydraulic order block. [3, 6, 7].

In the period 01.04.1983 - 2002, the invention is applied by ALFA, either as general ensemble (Figure 5), either as spare parts.
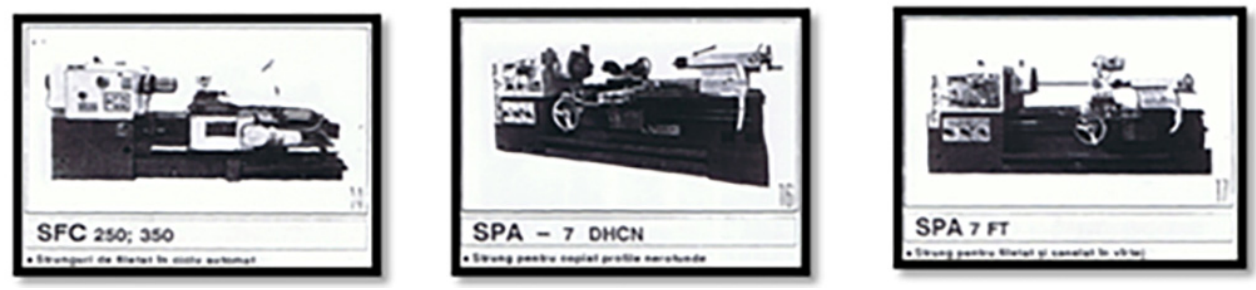

Fig. 5. Three from the ALFA lathes on which the patent was applied- Hydraulic order block. [3, 6, 7].

Starting with 31.03.1987 ALFA which has become company BETA doesn't pay the taxes for OSIM and the invention loses its rights.

Company BETA doesn't announce its inventors that she isn't interested anymore in paying the annual taxes for maintaining the invention in a protection regime. Starting with this date there doesn't exist any agreement regarding a remuneration model $[3,6,7]$.

However, company BETA continues to apply the old invention. The inventor's financial rights weren't negotiated between the inventor and the firm that has applied the invention. The company had the right to announce it, based on ART. 41/Law number 64/1991(This Law is applied in Romania), "The holder can renounce completely or in part to the patent, based on a written declaration registered at OSIM. For the inventions from art. 5 line 1, letter a) and line 2, as well as for the inventions that were the object of transfers according to art. 5 line. 1 letter. b), the holder of the patent is obliged to announce the inventor of its intention to renounce; at the inventor's request, the holder is obliged to transmit to him the right over the patent". As a consequence, this is a case of usage without a right $[3,6,7]$.

Company BETA has relied upon the stipulation from art.41/L64-91(This Law is applied in Romania): "The invention or part of it that has been renounced can be freely exploited by third parties". However, the reliance was made illegally because it can't be separated from the entire context of art.41.

Company BETA continues to apply its previous invention on technical work, without clearing its accounts with the inventors and by falsely applying part 4 from art.41/Law number 64/1991 (This Law is applied in Romania). As a result, the inventors sue company BETA this time for not respecting the CSJ's (The Supreme Court) decision of not producing anymore the object of the invention, as well as for additional damages. For this 
second period, company BETA hasn't realized any license or cession contracts with its right owners $[3,6,7]$.

The lawyers have invoked an extinctive prescription, based on Decree number 167/58 (This Decree is applied in Romania) acknowledging that there might exist a claim right but only because it is prescribed $[3,6,7]$.

\section{Based on the analyzed study, the following aspects were concluded:}

- in the case in which the owner is no longer interested in applying the invention, he has to announce the inventor so that he and OSIM can assume it. The exploitation of an invention without a contract represents fraud based on art.5, letter b)/Law number 64/1991 (This Law is applied in Romania) [7].

- according to Art.59/Law number 64/1991 (This Law is applied in Romania), the infraction of counterfeit was present, together with the rights of the rightful holder.

\section{Conclusions}

Managing specific intellectual property production risks can be a challenge, but must be considered more like a necessity for the creation of a powerful, modern and intuitive intellectual property management. This implies a knowledge of the protection legislation, knowing the IP risks preventive forms together with the action laws against intellectual property right breeches.

The importance of a performant management is also emphasized by the increasing number of expertise from this domain [7], which is foreseen as one of the most complex multidisciplinary scientific domains of analysis. This fact proves the necessity of evaluating compatible elements $[9,10]$ of some principles and sciences considered not long ago as separate: engineering-economy-law.

Besides the important contributions of enriching the specialty literature and based on the realized analysis, this study has however some limitations that can be structured as follows: - even though the risk analysis is a common theme in the national and international specialty literature, when we bring into discussion the specific intellectual property production risks, the situation changes due to the fact that they are less investigated and acknowledged by industrial companies.

- the impossibility to obtain detailed information regarding the financial situation of the analyzed company hasn't allowed us to apply the proposed formulas for evaluating the specific intellectual property production risks.

- the uncertainty of industrial companies regarding the disclosure of information regarding their activities and results has led to an analysis of the case study only from a legal perspective. Further investigations will have to apply these formulas by using dedicated software.

\section{References}

1. D. Săvescu, A. Budală, Intellectual Property in Romania and in some EU countries (Lux Libr. Pub. House, Brasov, 2008)

2. C. Greenhalgh, M. Rogers, Innovation Intellectual Property and Economic Growth (Prin. Univ. Press, Princeton and Oxford, 2010)

3. R. Pakocs, Quality and intellectual property risk management in the industrial companies (Ph.D, Tr. Univ., Brasov, 2015)

4. R. Pakocs, N. B. Lupulescu, Investigations regarding the management of specific intellectual property risks in companies from Romania (AFASES, Publ. House of "Henri Coanda" Air Force Acad., Brasov, 2016) 
5. R. Pakocs, N. B. Lupulescu, Need to implement a highly-performing intellectual property management in the technical-engineering field (AFASES, Publ. House of "Henri Coanda" Air Force Acad., Brasov, 2015)

6. R. Pakocs, N. B. Lupulescu, Risk management and risk type analysis specific to intellectual property in industrial companies (AFASES, Publ. House of "Henri Coanda" Air Force Acad., Brasov, 2014)

7. R. S. Fântână, Examination of goods import-export (ProUniv. Publ. House, 2010)

8. G. Secară, R. S. Fântână, General Management (ProUniv. Publi. House, 2010)

9. R. S. Fântână, N. Minculete, Extension of Liskov Substitution Principle and Application to Curriculum Management (Acta Poly. Hun., 2014)

10. R. F. Reilly, R. P. Schweihs, The Handbook of Business Valuation and Intellectual Property Analysis (The McGr. - Hill Comp., 2004)

11. D. Hillson, Project Risk Management: Future Developments ( Available at: www.riskdoctor.com/pdf-files/fut0798.pdf, 2004)

12. M. S. Mcnulty, Applied Risk Analysis of Complex Systems, The Third Conf. on Mathem. Meth. in Reliab., 4 (2002) 